\title{
Role of the oesophagus in asthma induced by the ingestion of ice and acid
}

\author{
NICOLA M WILSON, NOZHATCHUDRY, MICHAEL SILVERMAN
}

From the Department of Paediatrics and Neonatal Medicine, Royal Postgraduate Medical School, London

ABSTRACT Twelve Asian patients with a history of asthma exacerbated by ingestion of ice and acidic drinks were selected for study. To determine the site of response to ingested ice and acid they $\checkmark$ were challenged with ice or dilute hydrochloric acid, which was orally retained on one day and swallowed on another. On a third day a placebo was given. The airway response was assessed by? measuring $\mathrm{FEV}_{1}$ and the provocative concentration of histamine that reduced the $\mathrm{FEV}_{1}$ by at least ${ }_{-}^{\supset}$ $20 \%\left(\mathrm{PC}_{20}\right)$. There was no significant change in $\mathrm{FEV}_{1}$ or histamine $\mathrm{PC}_{20}$ after placebo or the orallyc retained challenges for the group as a whole or for any individual. After the ice and hydrochloric acid had been swallowed there was a small but statistically significant mean fall in $\mathrm{FEV}_{1}$, increasing $\vec{\oplus}$ to a maximum 90 minutes after ingestion, together with a significant increase in bronchial.. responsiveness. As conditioning of the inspired air would have been similar after orally retained and after swallowed ice or acid, the response is likely to be due to oesophageal stimulation. The mechanism of the response to oesophageal stimulation is unclear, but the slow time course seems to preclude a simple neural reflex.

Ingestion of ice ${ }^{1}$ and of dilute hydrochloric acid ${ }^{2}$ have both been shown to increase bronchial responsiveness in some asthmatic individuals. As soft drinks (pH about 3) are frequently served iced this could be a potential hazard for many individuals with asthma, particularly children.

The mechanism of this response is unclear but is likely to be due to stimulation of the upper gastrointestinal tract, although conditioning of the inspired air is a possibility. The study was designed to differentiate stimulation of the oropharynx and the oesophagus by assessing the airway response to orally retained and swallowed ice or hydrochloric acid; modification of the inspired air by the two methods should be similar. A test of bronchial responsiveness was included in the assessment as this has previously been shown to facilitate the detection of a positive response to oral challenge. ${ }^{1-3}$

\section{Methods}

SUBJECTS

Twelve patients giving a history of asthma exacer-

Address for reprint requests: Dr $\mathrm{N}$ M Wilson, Department of Paediatrics and Neonatal Medicine, Royal Postgraduate Medical School, London W12 0HS.

Accepted 9 February 1987 bated by ingestion of ice or acidic drinks were selected $\frac{\overrightarrow{0}}{3}$ from the asthma clinics at Hammersmith and Ealing Hospitals. Eight were children (6-15 years) and fouro were adults (21-57 years). Eight had severe asthma treated with inhaled steroids. All four adults hado응 symptoms that were difficult to control. All the subjects originated from the Indian subcontinent but allo the children were born in Britain. Inhaled bronchodilators were stopped for six hours and sustained $\delta$ action theophylline and cromoglycate for at least $12 ₹$ hours before testing.

\section{ORAL CHALLENGE PROCEDURE}

The subjects attended on three separate days. They were challenged with either ice or hydrochloric acid? according to their history. The active challenges of ice $N$ $(80 \mathrm{ml})$ or hydrochloric acid $(200 \mathrm{ml}, 0.01 \mathrm{~N})$, selected $\mathrm{\omega}_{\mathrm{W}}^{N}$ according to the history, were retained in the moutho on one study day and swallowed on another. Theo orally retained ice was contained in a polythene bag and sucked until it had melted. The resulting cooled $\stackrel{?}{?}$ saliva was gargled and spat out. The orally retained 0 hydrochloric acid was also gargled and spat out.o The placebo challenges consisted of a drink of 80 or $200 \mathrm{ml}$ of tap water as appropriate. The challenges were administered in random order for each subject by a third party. The hydrochloric acid and corresponding placebo were artificially sweetened with fiveo 
drops of saccharine solution and the swallowed active and placebo drinks, given double blind, were indistinguishable. The investigators were unaware which type of challenge had been given.

\section{ASSESSMENT OF BRONCHIAL RESPONSIVENESS}

On arrival in the laboratory on each study day the subjects rested for 10 minutes before measurement of FEV $_{1}$ (Vitalograph). This was then repeated at five minute intervals until a steady baseline was reached. A control histamine challenge test was performed by the method standardised by Cockcroft et al. ${ }^{4}$ Doubling concentrations of histamine solution $(0.03-16 \mathrm{~g} / \mathrm{l})$ were inhaled from a Wright's nebuliser until at least a $20 \%$ fall in $\mathrm{FEV}_{1}$ had occurred, to give the $\mathrm{PC}_{20}$ value. Thirty and 90 seconds after inhalation of each concentration of histamine the $\mathrm{FEV}_{1}$ was measured and the better of two measurements was accepted. An hour was allowed for recovery after completion of the control histamine test and the $\mathrm{FEV}_{1}$ was then measured again, before oral challenge and $5,10,15,30,60$, and 90 minutes afterwards. A second histamine test was then performed with the same set of histamine solutions and the same nebuliser. $\mathrm{PC}_{20}$ was calculated by interpolation of the last two points on the dose-response curve.

\section{STATISTICAL ANALYSIS}

Analysis of variance was used to assess statistical differences between groups, allowing for differences between patients. To assess the significance of individual responses the $95 \%$ confidence intervals for changes in $\mathrm{FEV}_{1}$ and $\mathrm{PC}_{20}$ that occurred after placebo challenge were calculated. For $\mathrm{PC}_{20}, \log _{e}$ transformation was used for all statistical analysis. The $95 \%$ confidence interval for change in $\mathbf{P C}_{20}$ after placebo was calculated from the standard deviation of the 2nd:1st $\mathbf{P C}_{20}$ ratio followed by antilog ${ }_{e}$ conversion.

\section{Results}

Twelve subjects completed the study and one subject was studied twice, with both ice and acid. In three there was less than a $10 \%$ fall in $\mathrm{FEV}_{1}$ and no significant change in histamine $\mathrm{PC}_{20}$ after oral challenge on any of the three study days. As an airway response to ingested ice or acid had not been demon, strated, these three subjects were excluded from further analyses. In six subjects a response was demonstrated after challenge with ice and in four after acid. Analysis of variance showed no difference in response between those subjects challenged with ice and those challenged with acid on the three study days. The 10 results have therefore been combined for assessment of mean changes in $\mathrm{FEV}_{1}$ after challenge

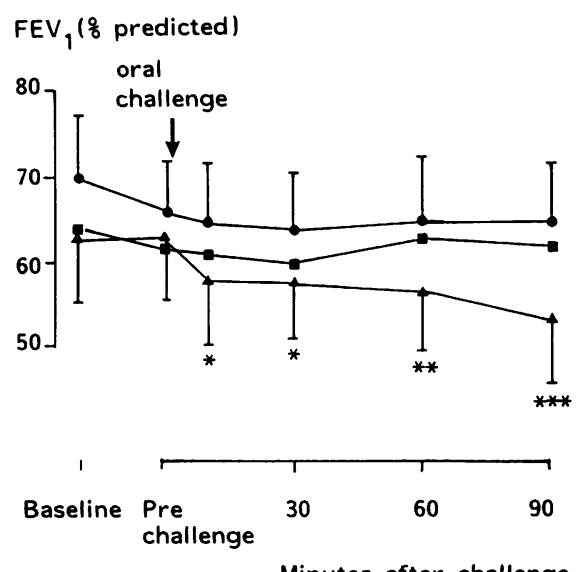

Fig 1 Results of ice and hydrochloric acid challenge combined $(n=10)$ to show the effect on mean (SE) FEV . - Placebo; orally retained challenge; $\Delta$ swallowed challenge.

on each study day (fig 1). To calculate the $95 \%$ confidence intervals for change in $\mathrm{FEV}_{1}$ and $\mathrm{PC}_{20}$ after active challenge we used the mean results of the 10 subjects on the placebo study days.

There were no significant mean differences in baseline $\mathrm{FEV}_{1}$ or control $\mathrm{PC}_{20}$ between the three study days. After placebo or orally retained ice or acid mean $\mathrm{FEV}_{1}$ and $\mathrm{PC}_{20}$ did not differ significantly from

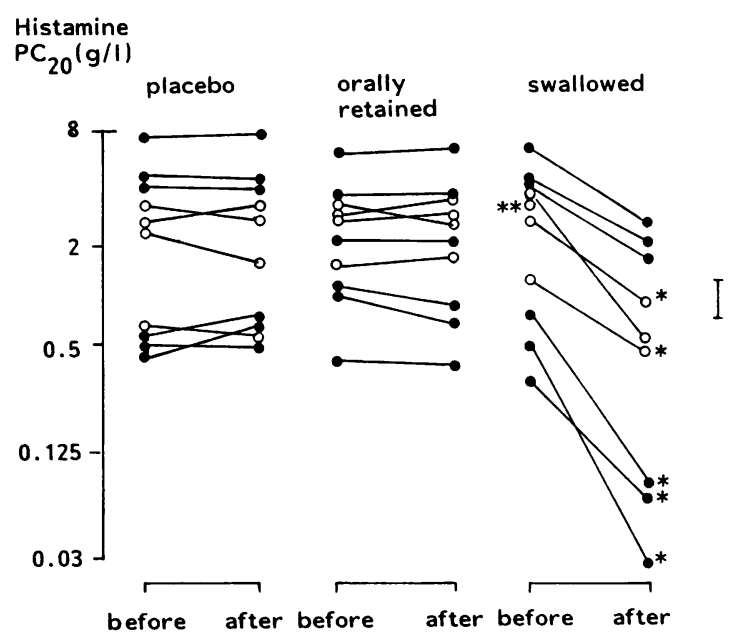

Fig 2 Individual histamine $P C_{20}$ values (concentrations causing at least a $20 \%$ fall in FEV $V_{1}$ ) before and after challenge with ice (O) and hydrochloric acid ( $O)$, orally retained and swallowed and corresponding placebos. The bar shows $95 \%$ confidence interval of changes in $P C_{20}$ after placebo challenge. ${ }^{* *}$ No post hydrochloric acid histamine $P C_{20} ;{ }^{*} F E V_{1}$ fell $>10 \%$. 
control values obtained before oral challenge. After the swallowed active challenges, however, there was a small but significant fall in mean $\mathrm{FEV}_{1}$ at each time point (fig 1). The $\mathrm{FEV}_{1}$ was significantly lower at 90 than at 10 minutes after challenge $(p<0.02)$. There was also a significant fall in mean $\mathbf{P C}_{20}$ after the swallowed ice and acid ( $p<0.001)$, but this was also associated with a significantly lower mean baseline FEV $_{1}$ before the second test $(\mathrm{p}<0.001)$.

The $95 \%$ confidence interval for change in FEV after placebo challenge was found to be $\pm 10 \%$ and for change in $\mathrm{PC}_{20} \pm 0.75$ histamine dilutions. No individual subject showed a greater than $10 \%$ fall in $\mathrm{FEV}_{1}$ or a significant fall in $\mathrm{PC}_{20}$ after the orally retained ice or acid. After the swallowed ice and acid six subjects showed $11-50 \%$ falls in $\mathrm{FEV}_{1}$ but in only two was it over $20 \%$. In one subject it was impossible to perform a histamine test because of the bronchoconstriction induced by ice ingestion. A significant fall in $\mathbf{P C}_{20}$ was seen in all the remaining subjects (fig 2).

\section{Discussion}

We found that orally retained ice or dilute hydrochloric acid had no significant effect on airway function, whereas swallowed ice or acid provoked overt bronchoconstriction in some and an increase in bronchial responsiveness to nebulised histamine 90 minutes after ingestion in all subjects. This suggests that the oesophagus was the site of the event that initiated the sequence leading to airway narrowing or hyperresponsiveness.

For the group as a whole and for six individual subjects, after the ice or acid had been swallowed baseline $\mathrm{FEV}_{1}$ was lower before the second histamine test, and this could be partly responsible for the finding of increased responsiveness. ${ }^{5}$ Even in the four subjects in whom the difference in baseline $\mathrm{FEV}_{1}$ before the two histamine tests was less than $10 \%$, there could have been an increase in peripheral airway resistance, undetected by the measurement of FEV . $^{\text {. }}$ This could have resulted in an increase in central deposition of the histamine aerosol, ${ }^{6}$ with a consequent higher concentration on the central airway receptors and hence a reduction in $\mathrm{PC}_{20}$. Indeed, aerosol penetrance has been suggested as a sensitive test for small airway function. ${ }^{7}$ Conventional tests of peripheral airways obstruction are controversial ${ }^{8}$ and would have been invalid in the presence of the large airways obstruction, which was present in many of the subjects in this study. In contrast, the measurement of histamine responsiveness is simple and reproducible even in the presence of poor lung function, and the $\mathrm{PC}_{20}$ was used in this study simply to facilitate the detection of an airway response to orat: challenge.

The findings are unlikely to be spurious as both thळ $\mathrm{FEV}_{1}$ and histamine $\mathrm{PC}_{20}$ were shown to be reproducible after placebo and after the orallys retained active challenge. The hydrochloric acid was given double blind and the active and placebo drinks were indistinguishable. The subjects would have been aware of swallowing ice and it remains a possibility although unlikely, that the response was psycho $\vec{\omega}$ genically determined. The $F E V_{1}$ was, however, lowero 90 minutes than 10 minutes after challenge after both ice and acid, and previous experience has shown thats the $\mathrm{PC}_{20}$ is also lower 90 minutes than 30 minutes after ingestion of ice. ${ }^{1}$ The pattern of the responser makes a psychogenic mechanism unlikely.

This study shows that it was necessary for the ice and hydrochloric acid to be swallowed for an asthmatic response to occur. Inhalation of both cold air ${ }^{2}$, and acidic aerosols ${ }^{10}$ have been shown to cause bronchoconstriction. As conditioning of the inspiredo air during challenge by the hydrochloric acid and ice was likely to be similar whether the substances were swallowed or orally retained, cooling or acidificatione of the inspirate is unlikely to be the explanation.

The stomach already contains hydrochloric acid. Ingested ice, having been sucked and swallowed, would have neared body temperature by the time it reached the stomach, so the site of the stimulus iso likely to be the oesophagus. There was no clinical evidence of any oesophageal dysfunction in any of the subjects. All the subjects, however, originated from: the Indian subcontinent, so perhaps oesophagitis was more likely because of their highly spiced diet.

The mechanism whereby oesophageal stimulation: can cause an airway response is not obvious. There is 3 . evidence from animal studies of both thermal ${ }^{11}$ and acid sensitive ${ }^{12}$ vagal receptors in the oesophagus. In dogs with induced oesophagitis oesophageal acidification with $0 \cdot 1 \mathrm{~N}$ hydrochloric acid resulted in bronchoconstriction, which could be abolished by vagal section. ${ }^{12}$ Hydrochloric acid $(0 \cdot 1 \mathrm{~N})$ infused into the oesophagus has also been shown to induce $N$ bronchoconstriction in both adults ${ }^{1314}$ and $N$ children $^{15}$ with asthma in the presence of oeso-N phagitis. In the same studies subjects without $\omega$ evidence of oesophagitis failed to show a pulmonary? response to oesophageal acidification. It is clear from these and other studies that consider the role of gastro-oesophageal reflux in asthma that not all ${ }^{+}$ individuals with hyperresponsive airways respond to $\frac{0}{0}$ oesophageal stimulation, although some asthmatic $\overrightarrow{\mathbb{D}}$ subjects without symptoms referrable to the upper $\frac{\mathbb{P}}{\mathbb{P}}$ gastrointestinal tract showed increased bronchial $\stackrel{\circ}{\circ}$ responsiveness after a drink of the hydrochloric acid as dilute as $0 \cdot 001 \mathrm{~N}^{2}(\mathrm{pH} \mathrm{3 \cdot 1)}$. 
Could a vagal reflex in certain susceptable subjects, particularly those with oesophageal mucosal damage, account for the results of this study? The similarity of the response to the two challenge substances would suggest a common pathway but the timing of the response, maximal at least 90 minutes after challenge, makes a simple reflex unlikely. Since bronchoconstriction after cooling of airways can result in a fall in oesophageal temperature ${ }^{16}$ during oesophageal cooling from ingestion of ice arguably the reverse could occur. In this study the bronchoconstriction following ice ingestion increased during the 90 minutes over which the $\mathrm{FEV}_{1}$ was measured, a pattern not seen with cold air inhalation, which makes airway cooling an unlikely explanation. Cooling of the face ${ }^{17}$ and body ${ }^{1819}$ have also been reported to produce bronchoconstriction, persisting for up to 15 minutes after return to normal temperature. ${ }^{19}$

Another possibility is non-immunologically provoked mediator release, similar to that seen with cold induced urticaria. ${ }^{20}$ The timing of the response could suggest production of membrane derived mediators such as platelet activating factor or leukotrienes, both of which have been associated with increased bronchial responsiveness. ${ }^{21} 22$

The subjects selected for this study all originated from the Indian subcontinent. The reason for this selection was to obtain a sample of patients with a high yield of positive responses to the oral challenges. Asians have previously been reported as more frequently giving a history of asthma induced by ice and fizzy drinks (pH 3.0) than non-Asians. ${ }^{23}$ Although non-Asian subjects are known to respond to a drink of hydrochloric acid, ${ }^{2}$ there is little published evidence to confirm that they show an asthmatic response to ingested ice. All the subjects in one previous study demonstrating ice induced asthma were Asian. ${ }^{1}$ There is one case report ${ }^{24}$ of ingestion of ice cream that caused nearly fatal asthma in a patient of unspecified ethnic origin, and early references to ice ingestion causing wheeze as part of a syndrome of "physical allergy" probably refer to non-Asian patients. ${ }^{25}$ Asians with asthma seem unlikely to be alone in this susceptibility.

This study has shown that oesophageal stimulation by ingestion of ice and acid can exacerbate asthma. The idea of the oesophagus as a potential site for bronchoconstrictive stimuli is consistent with the frequently reported association of gastro-oesophageal reflux and asthma. ${ }^{26} 27$ The actual mechanism, however, remains unclear.

We would like to thank the Asthma Research Council and Boehringer Ingelheim Ltd (UK) for financial support. We are also grateful to Vic Aber (Department of
Statistics, Royal Postgraduate Medical School) for help with statistics.

\section{References}

1 Wilson NM, Dixon C, Silverman M. Increased bronchial responsiveness caused by ingestion of ice. Eur J Respir Dis 1985;66:25-30.

2 Wilson NM, Charette L, Thomson AH, Silverman M. Gastro-oesophageal reflux and childhood asthma: the acid test. Thorax 1985;40:592-7.

3 Wilson N, Vickers H, Taylor G, Silverman M. Objective test for food sensitivity in asthmatic children: increased bronchial reactivity after cola drinks. $\mathrm{Br}$ Med J 1982;284:1226-8.

4 Cockcroft DW, Killian DN, Mellor JJA, Hargreave FE. Bronchial reactivity to inhaled histamine: a method and clinical survey. Clin Allergy 1977;7:235-43.

5 Benson MK. Bronchial hyper-reactivity. $\mathrm{Br} J$ Dis Chest 1975;69:227-37.

6 Larbe BL, Swift DL, Wagner HN, et al. The effect of bronchial obstruction on central airway deposition of a saline aerosol in patients with asthma. Am Rev Respir Dis 1986;133:740-3.

7 Dolovich MB, Sanchis J, Rossman C, Newhouse MT. Aerosol penetrance: a sensitive test for peripheral airway obstruction. J Appl Physiol 1976;40:468-71.

8 Landau L, Mellis CM, Phelan PD, Bristowe B, McLennan L. Small airways disease in children: no test is best. Thorax 1979;34:217-23.

9 Millar JS, Nairn JR, Unkles RD, McNeill RS. Cold air and ventilatory function. $B r J$ Dis Chest 1965;59:23-7.

10 Utell MJ, Morrow PE, Speers DM, Darling J, Hyde RW. Airway responses to sulphate and sulphuric acid aerosols in asthmatics. Am Rev Respir Dis 1983;128: 444-50.

11 Ouazzoni T, Mei N. Electrophysiological properties and the role of the vagal thermoreceptors of the lower oesophagus and stomach of the cat. Gastroenterology 1982;83:995-1001.

12 Mansfield LE, Hameister HH, Spaulding HS, Smith NJ, Glab N. The role of the vagus nerve in airway narrowing caused by intraoesophageal hydrochloric acid provocation and oesophageal distension. Ann Allergy 1981;47:431-4.

13 Kjellén G, Tibbling L, Wranne B. Bronchial obstruction after oesophageal acid perfusion in asthmatics. Clin Physiol 1981;1:285-92.

14 Spaulding HS, Mansfield LE, Stein MR, et al. Further investigations of the association between gastrooesophageal reflux and bronchoconstriction. $J$ Allergy Clin Immunol 1982;69:516-21.

15 Davis RS, Larsen GL, Grunstein MM. Respiratory response to intraoesophageal acid infusion in asthmatic children during sleep. $J$ Allergy Clin Immunol 1983;72:393-8,

16 Deal EC, McFadden ER, Ingram RH, Jaeger JJ. Oesophageal temperature during exercise in asthmatic and non-asthmatic subjects. $J$ Appl Physiol 1979;46: 484-90.

17 Josenhans WT, Melville GN, Ulmer WT. The effect of 
facial cold stimulation on airways conductance in healthy man. Can J Physiol Pharmacol 1969;47: 543-57.

18 Chen WY, Horton DJ. Airways obstruction in asthmatics induced by body cooling. Scand J Respir Dis 1978;59:13-20

19 Ramsey JM. Time course of bronchoconstrictive response in asthmatic subjects to reduced temperature. Thorax 1977;32:26-8.

20 Gorevic PD, Kaplan AP. The physical urticarias. Int $J$ Dermatol 1980;19:417-35.

21 Mazzoni L, Morley J, Page CP, Sanjar S. Induction of airway hyper-reactivity by platelet activating factor in the guinea pig. J Physiol 1985;365:107.
22 O'Byrne PM, Leikauf GD, Aizawa $\mathrm{H}$, et al. Leukotriené $\mathrm{B}_{4}$ induces airway hyper-responsiveness in dogs. $\overline{\vec{b}}$ Appl Physiol 1985;59:1941-6.

23 Wilson NM. Food related asthma: a difference betweef two ethnic groups. Arch Dis Child 1985;60:861-5.

24 Henderson A. Near fatal asthma after eating deep frozen ice cream. J Army Med Corps 1983;129:52-3.

25 Swineford O. Physical allergy. J Allergy 1935;6:175-830

26 Berquist WE, Rachelefsky GS, Kadden M, et al. Gastro-oesophageal reflux associated with recurrent pneu? monia and chronic asthma in children. Pediatrica 1981;68:29-35.

27 Mays EE. Intrinsic asthma in adults: association wit gastro-oesophageal reflux. $J A M A$ 1976;236:2626-8. 